\title{
General practitioners' training for, interest in, and knowledge of sports medicine and its organisations
}

\author{
D G W Buckler
}

\begin{abstract}
Objectives-To assess the training and interest of a group of general practitioners in the area of sport and exercise medicine, and the organisations representing the specialty.
\end{abstract}

Design-A postal questionnaire using a Likert scale in a previously piloted set of questions.

Subjects-275 general practitioners registered with the Northampton Regional Health Authority.

Main outcome measurementsResponses to questions designed to assess training and interest in sport and exercise medicine.

Results-A response rate of $87.6 \%$ was achieved. It was found that $72.7 \%$ of the responding general practitioners felt inadequately trained to practice sport and exercise medicine. Some $76.0 \%$ would welcome more training and $36.4 \%$ felt that their undergraduate orthopaedic training was of no use in primary care. Many $(63.6 \%)$ of the general practitioners believed that the current NHS cannot sustain sport and exercise medicine, and there was uncertainty as to whether it is currently a recognised specialty, although $60.4 \%$ felt that it should be. General practitioners listed lack of facilities $(53.1 \%)$, lack of training $(42.9 \%)$, and lack of time $(38.2 \%)$ as the main problems in practicing sport and exercise medicine in primary care within the current NHS.

Conclusions-General practitioners feel undertrained in sport and exercise medicine at both undergraduate and postgraduate level; they have a perceived need for more training and show an interest in the subject. There is scope for improving the value of undergraduate orthopaedic training. General practitioners wish to see sport and exercise medicine recognised as an NHS specialty but fear that this is not sustainable under current conditions. There is confusion among general practitioners about the current sport and exercise medicine organisations.

(Br f Sports Med 1999;33:360-364)

Keywords: training; general practitioners; undergraduate; postgraduate; British Association of Sport and Medicine; National Sports Medicine Institute
The National Lottery has set aside funds for the establishment of a centre of excellence for sport and exercise medicine in Sheffield with regional centres to follow. The setting up of a network of sport medicine facilities will need the cooperation of general practitioners; indeed it has been suggested that the bulk of generalist sports physicians must come from the ranks of general practice. ${ }^{1}$ There is little information on the level of knowledge of sport and exercise medicine within the general practice community. Neither is there documented evidence of the level of interest in this emerging specialty among general practitioners nor of their attitudes towards sport and exercise medicine, treating casualties of sports, and the role of sport and exercise medicine in the NHS. If future provisions are to be made for primary health care sport medicine, baseline information is needed.

A survey of general practitioners in Northamptonshire was therefore conducted to evaluate these issues.

\section{Methods}

SAMPLING FRAME

The sampling frame consisted of the names of all general practitioners held on computer record at Northampton Regional Health $\mathrm{Au}-$ thority. This was considered to be accurate and complete, as every general practitioner who treats patients within the Northamptonshire area must be registered with this body.

There were 319 general practitioners registered in July 1996. All were included in the survey and sent a postal questionnaire. Four questionnaires were returned because the doctors were on long term sick leave, and three of the general practitioners had retired; two of the latter had passed the questionnaire on to their replacements. This gave a final sampling frame of 314 general practitioners, about whom the health authority provided demographic information.

\section{QUESTION SELECTION}

A literature search showed no previous similar work on which we could base our questions. The questions were therefore chosen by consultation with leaders in the field of sport and exercise medicine, general practice, and public health medicine. The questions were designed to address the study objectives, which 


\begin{tabular}{|c|c|c|c|c|c|}
\hline & \multicolumn{4}{|l|}{ Agree } & \multirow{2}{*}{$\begin{array}{l}\text { Disagree } \\
5\end{array}$} \\
\hline & 1 & 2 & 3 & 4 & \\
\hline I have an interest in sport and exercise medicine & $11.6(32)$ & $30.5(84)$ & $34.9(96)$ & $17.8(49)$ & $5.1(14)$ \\
\hline I have adequate training in sport and exercise medicine & $0.7(2)$ & $6.5(18)$ & $20.4(56)$ & $41.1(113)$ & $30.9(85)$ \\
\hline General practitioners have the skills to treat sports injuries well & $1.5(4)$ & $8.7(24)$ & $34.9(96)$ & $42.2(116)$ & $12.7(35)$ \\
\hline I find sports players are difficult to treat in general practice due to my lack of training & $9.8(27)$ & $33.1(91)$ & $31.3(86)$ & $21.1(58)$ & 4.7 (13) \\
\hline I find sports players are difficult to treat in general practice due to my lack of time & $10.2(28)$ & $28.0(77)$ & $32.4(89)$ & $25.5(70)$ & $3.6(10)$ \\
\hline I find sports players are difficult to treat in general practice due to my lack of facilities & $13.5(37)$ & $39.6(109)$ & $23.3(64)$ & $20.4(56)$ & $2.9(8)$ \\
\hline Encouraging people to exercise is an integral part of my job as a general practitioner & $55.6(153)$ & $35.6(98)$ & $6.2(17)$ & $1.8(5)$ & $0.4(1)$ \\
\hline I enjoy treating sports people & $14.9(41)$ & $32.4(89)$ & $32.4(89)$ & $15.6(43)$ & $4.0(11)$ \\
\hline The current NHS cannot deal with the demands of sport and exercise medicine & $24.7(68)$ & $38.9(107)$ & $22.2(61)$ & $10.9(30)$ & $3.3(9)$ \\
\hline The current NHS should not be expected to deal with the demands of sport and exercise medicine & $12.0(33)$ & $22.2(61)$ & $24.7(68)$ & $28.7(79)$ & $12.4(34)$ \\
\hline Sport and exercise medicine is a recognised NHS specialty & $6.5(18)$ & $26.2(72)$ & $30.2(83)$ & $24.7(68)$ & $10.2(28)$ \\
\hline Sport and exercise medicine should be a recognised NHS specialty & $21.1(58)$ & $39.3108)$ & $24.0(66)$ & $9.5(26)$ & $4.7(13)$ \\
\hline I am a keen sports player & $21.8(60)$ & $26.2(72)$ & $25.1(69)$ & $16.7(46)$ & $9.8(27)$ \\
\hline I am a keen sports viewer & $21.5(59)$ & $24.4(67)$ & $23.3(64)$ & $16.4(45)$ & $14.5(40)$ \\
\hline
\end{tabular}

Values are expressed as percentages (n).

were to assess the general practitioner's knowledge, training in, and attitudes to sport and exercise medicine.

To avoid confusion, a working definition of sport and exercise medicine was given at the top of the questionnaire, and general practitioners were asked to provide answers using this definition: "Medicine for people who require treatment or advice as a consequence of their involvement in sport or exercise".

The questionnaire was piloted on ten general practitioners who were then interviewed to assess any problems. Two of the questions were modified and one was discarded on advice obtained at these consultations.

The general practitioners were asked to grade their responses on a five point Likert scale, from strongly agree to strongly disagree.

STATISTICAL ANALYSIS

To identify significant differences between responders and non-responders, these two groups were compared by age, sex, and fundholding status of the practice. The ages and number of years in practice were divided into 10 year subgroups. These subgroups were analysed against the nominal data provided from the Likert scales using $\chi^{2}$ tests.

A probability level of $\mathrm{p}<0.05$ (two sided) was used throughout to denote statistical significance. When numbers were not large enough for $\chi^{2}$ tests, the data were collapsed-for example, combining the categories "strongly agree" and "agree".

\section{Results}

RESPONSE RATES

A total of 275 responses were received from the 314 general practitioners contacted giving a response rate of $87.6 \%$. The mean (SD) age of the responders was 43.6 (8.3) years. The age distribution was representative of the country as a whole, using demographic information from the regional health authority.

In all, $78.7 \%(n=217)$ of responders were men and $52.0 \%(n=143)$ were in fundholding practices. The rate of fundholding was slightly lower than the national average.

The 39 non-responders were similar to the group of responders in terms of these characteristics.
TRAINING AND INTEREST IN SPORT AND EXERCISE MEDICINE

Only 17 respondents $(6.2 \%)$ had received undergraduate training in sport and exercise medicine, and this was exclusively as a small part of an orthopaedic or rheumatology attachment. There were no reports of studying sport and exercise medicine as a separate specialty. Nearly two thirds $(62.9 \%)$ of the general practitioners had received no postgraduate training in sport and exercise medicine. Of the $37.1 \%(\mathrm{n}=102)$ who had received postgraduate training, only $3 \%(n=8)$ had had more than one weeks training. Most $(76.0 \%$; $\mathrm{n}$ $=209$ ) stated that they would like more training. Some $36.4 \%(n=100)$ found that the orthopaedic training that they had received was of no use to them as general practitioners.

Table 1 shows that there was a fairly even split between those interested and those not interested in sport and exercise medicine; $22.9 \%(n=63)$ had little interest and 5.1\% ( $=14$ ) strongly disagreed with the statement "I have an interest in sport and exercise medicine". Only $7.2 \%(\mathrm{n}=20)$ felt that they personally had the training to treat athletes well, while $72.7 \%(n=200)$ felt undertrained. Similarly, when asked about the training of the profession in general, again only $10.2 \%(\mathrm{n}=$ 28) believed that athletes will meet an adequately skilled general practitioner, and $54.9 \%(n=151)$ will be underskilled.

Almost half $(48.0 \% ; n=132)$ of the general practitioners claimed to be current or previous sports participants, and $26.5 \%(n=73)$ were mainly sedentary. The sports participants were more likely to be interested in sport and exercise medicine ( $p=0.001)$, to have sought out further training $(\mathrm{p}=0.001)$, and to enjoy treating sports people $(\mathrm{p}<0.001)$.

Younger general practitioners, aged less than 40 , were more likely to be interested in sport and exercise medicine $(\mathrm{p}=0.001)$ and more likely to welcome further training $(p=0.001)$.

Some $42.9 \%(n=118)$ of the general practitioners thought sport and exercise medicine was difficult to apply in general practice because of lack of training. A further $38.2 \%$ (n $=105$ ) cited lack of time as a problem, but the biggest single problem appeared to be lack of facilities $(53.1 \% ; n=146)$. 
Table 2 Responses of general practitioners to questions on organisation of sport and exercise medicine

\begin{tabular}{lrr}
\hline & $\%$ & $N o$ \\
\hline Which of the following organisations have you heard of? & & \\
BASM only & 48.7 & 134 \\
NMSI only & 2.9 & 8 \\
Both & 16.7 & 46 \\
Neither & 29.8 & 82 \\
Missing & 1.8 & 5 \\
Who is in your opinion best placed to run sport and exercise medicine? & \\
Royal College of Surgeons (Orthopaedics) & 0.7 & 2 \\
Royal College of General Practitioners & 1.1 & 3 \\
BASM & 26.1 & 72 \\
NMSI & 3.3 & 9 \\
Joint group & 15.9 & 44 \\
Unsure & 46.0 & 126 \\
Missing & 6.9 & 19 \\
Was your orthopaedic training of use to you in primary care? & & \\
Yes & 61.1 & 168 \\
No & 36.4 & 100 \\
Missing & 2.5 & 7 \\
\hline
\end{tabular}

Most $(90.2 \% ; \mathrm{n}=251)$ general practitioners agreed that encouraging people to exercise is an integral part of their job, but $2.2 \%(n=6)$ disagreed with this.

Almost half $(47.3 \% ; n=120)$ of the general practitioners questioned enjoyed treating sports people, but $19.6 \%(\mathrm{n}=54)$ obtained no enjoyment at all from doing so.

There were no gender differences in amount of postgraduate training, interest, or enjoyment.

THE NHS AND SPORT AND EXERCISE MEDICINE There was considerable agreement among the general practitioners that the NHS cannot currently cope with sport and exercise medicine. Only $14.2 \%(\mathrm{n}=39)$ felt that it could cope whereas $63.6 \%(n=175)$ felt that the demands of sport and exercise medicine are unsustainable in the present structure (table 1). Some $41.1 \%(\mathrm{n}=133)$ felt that the NHS should sustain this specialty, whereas $34.2 \%(\mathrm{n}=94)$ disagreed, $24.7 \%(\mathrm{n}=68)$ being undecided.

Approximately equal numbers of general practitioners agreed $(32.7 \% \mathrm{n}=90)$ or disagreed $(34.9 \% \mathrm{n}=96)$ that sport and exercise medicine was a recognised NHS specialty, with $30.2 \%(n=83)$ having no set views. However, there was a firm feeling that sport and exercise medicine should be a recognised specialty, $60.4 \%(\mathrm{n}=166)$ agreeing compared with $14.2 \%(n=39)$ who disagreed.

KNOWLEDGE OF THE ORGANISING BODIES WITHIN SPORT AND EXERCISE MEDICINE

Over half $(65.4 \% ; \mathrm{n}=180)$ of the general practitioners had heard of the British Association of Sport and Medicine (BASM), 19.6\% $(\mathrm{n}=54)$ had heard of the National Sports Medicine Institute (NSMI), $16.7 \%(\mathrm{n}=46)$ had heard of both, and $29.8 \%(n=82)$ had heard of neither (table 2). The responses to questions about who should run sport and exercise medicine showed that a large proportion $(46 \% ; n=126)$ were unsure, although $26.1 \%(\mathrm{n}=72)$ suggested BASM and $15.9 \%$ $(\mathrm{n}=44)$ preferred a combined college initiative, with few in favour of a single Medical Royal College.

\section{Discussion}

The government continues to tell people to exercise, ${ }^{2}$ this study confirms that general practitioners are encouraging people to exercise, and people have more leisure time and are playing more sport." In fact, there is "an epidemic of sport", ${ }^{4}$ but as yet no epidemic of sport and exercise medicine. General practitioners are not ready to deal with this epidemic. It is work that they are not trained to do.

Between 1975 and 1992, 1500 postgraduates, both doctors and physiotherapists, attended BASM introductory courses in sport and exercise medicine. ${ }^{5}$ These courses do an excellent job in educating general practitioners about the problems associated with sport and exercise, but inevitably it is the people who are already interested who attend. ${ }^{5}$ Those who are sufficiently interested can attend more advanced courses, and, provided that enthusiasm, time, and money do not run out, sit and pass a diploma examination run by either the Scottish Royal Colleges Board for Sports Medicine or the Royal Society of Apothecaries in London. This is the equivalent of a Royal College Diploma examination in that it should recognise the person as being ready for further training"; however, there is currently no "next step" to the ladder. There is some evidence that interest in sport and exercise medicine is increasing. Three universities have started MSc courses, and interest is increasing in the United States. ${ }^{6}$ In the United Kingdom it has been suggested that the lack of a clearly defined career structure is a problem, as is the confusion about who is actually running sport and exercise medicine in the country. ${ }^{7}$ This has led to the setting up of the Intercollegiate Academic Board of Sport and Exercise Medicine by the Academy of Medical Royal Colleges, the remit of which is to formulate principles upon which the specialty of sport and exercise medicine can be developed.

This work can only be seen as a snapshot of the views of general practitioners. The lack of reliability testing such as test-retest analysis means that there may be some temporal instability and it cannot be shown whether interest is increasing (as the author suspects it may be). It is a baseline for further studies.

The sample was Northamptonshire general practitioners; it is difficult to predict how accurately these views can be extrapolated to the rest of the United Kingdom.

Despite the clear definition used in the questionnaire, sports medicine means different things to different general practitioners and there was the potential for inconsistencies.

However, the high response rate gives confidence in the results and enables us to draw some conclusions and goes some way towards defining, if not answering, some of the questions that the Intercollegiate Academic Board of Sport and Exercise Medicine will face in introducing sport and exercise medicine into primary care. This work shows a clearly perceived need for training in sport and exercise medicine for general practitioners, who feel undertrained both personally and as a profession. There is considerable evidence that 
general practitioners would welcome training and find it useful. Sport and exercise medicine is work that most general practitioners enjoy and find interesting. Training could be carried out at an undergraduate level or as part of a vocational training scheme. There is considerable scope for improving the value of undergraduate orthopaedic training to increase the relevance for general practitioners.

Who should provide this training? If most future sports physicians are to come from general practice, there will need to be postgraduate training schemes with a defined career structure. However, the lack of a recognised Royal College causes confusion over who speaks for the specialty. This lack of consensus is evident. About $66 \%$ of these general practitioners had heard of BASM, only $17 \%$ were aware of the existence of both BASM and NMSI, and 30\% were not aware of the existence of either. These figures should be of concern to these organisations. General practitioners appear to be divided as to who should run sport and exercise medicine: $26.1 \%$ suggested BASM, $15.9 \%$ suggested a joint group, and $46.0 \%$ were unsure. If sport and exercise medicine is to become a recognised specialty, will it be hospital based or will primary care sports physicians play an important role?

The main problem facing general practitioners in primary care is lack of facilities, particularly access to physiotherapists, but lack of time and lack of training also appear to compromise their ability to practice sport and exercise medicine. There is doubt among general practitioners as to whether sport and exercise medicine is sustainable within the current NHS. There is good evidence, however, that they would like to see it as an NHS specialty. However, general practitioners are likely to want any facility that would aid their patients, and it would be interesting to see sport and exercise medicine rated against other specialties in a system similar to the Oregon experiment. $^{8}$

For the regular or budding sports person, the message that $19.6 \%$ of general practitioners do not enjoy treating sports people, $22.9 \%$ have no interest in sport and exercise medicine, and only $7.2 \%$ feel that they have the necessary skills is worrying. Even those general practitioners who do enjoy dealing with their problems are likely to be untrained or undertrained and lack time and facilities. General practitioners are fighting to meet increased demands from many sources and need to control their workload to prevent burnout. ${ }^{9}$ Sports people need help to access general practitioners who are interested and trained.

Will sport and exercise medicine become a recognised specialty and when will there be a unified body speaking for it? A body is needed to organise training of all doctors entering general practice to increase the level of training within primary care. There also needs to be a recognised postgraduate career structure for doctors wishing to become involved in primary care sport and exercise medicine. Without these systems in place to provide leadership and education, this work suggests that general practitioners as a profession are not yet ready to provide a service for people who need advice and treatment as a result of their involvement in sport or exercise.

I would like to acknowledge Dr Carol Coupland for overseeing the writing up of this paper, Dr Heather Roberts for questionnaire skills, Dave Williams for Epi info skills, Dr Joan Bassey for common sense, Dr Mark Batt for comments on the discussion, and the Northampton Regional Health Authority.

1 Hutson M. Why sports injury clinics? [Letter] BMf 1987;295:1210.

2 Department of Health. More people, more active, more often. Physical activity in England, a consultation paper. London: Depatment of Health, 1995.

3 Department of Health. The health of the Nation. London: HMSO, 1992

4 King JB. Sports medicine. F R Soc Med 1986;79:441-2.

5 Anonymous. Sport and exercise medicine: where are the specialists? [Editorial] Br F Sports Med 1992;26:75

6 Fick DS, Tearse DS. Undergraduate sports medicine. Acad Med 1994;69:901.

7 Anonymous. A united centre? [Editorial] $\mathrm{Br} \mathcal{F}$ Sports Med 1990;24:3.

8 Ham C. Retracing the Oregon Trail. The experience of rationing and the Oregon health plan. BMF 1998;316: 1965-9.

9 Kirwan M, Armstrong D. Burnout in general practitioners. fournal of the Royal College of General Practitioners 1995;45: 259-260.

\section{Take home message}

There is a perceived need for and interest in postgraduate training in sport and exercise medicine among general practitioners, and undergraduate orthopaedic training could be made more relevant to primary care. Most general practitioners would like to see sport and exercise medicine as a recognised NHS specialty. There is confusion among general practitioners about the organisations that represent sport and exercise medicine. 


\section{Commentary}

This paper makes interesting and provocative reading for all involved in, or with informed views about, sports medicine. As the results "feel right", I focus attention on how they were achieved. This does not deny their face value, but contextualises them and suggests improvements for the next wave of studies. In best practice, extensive effort goes into questionnaire design. Questionnaires should be checked for reliability and validity, and refined, checked, and refined again before being used in a main study. Explaining the literature search strategy (what, where, etc) and how it was used helps to identify content validity. Test-retest data would have helped to gauge the consistency of responses. Despite an excellent response rate, appropriate analysis, and clear discussion, we can question some basic assumptions of the study. Did the general practitioners use the required definition of sport and exercise medicine? Did they hold a single mental picture-a professional athlete, an aerobic instructor, or a weekend warrior-or emphasise specific treatment successes? These issues threaten the internal validity of the responses. By closely addressing these issues, further questionnaire studies within sports medicine will achieve the vital qualities of reliability and validity.

J MCKENNA

Bristol

\section{Commentary}

This is a useful paper on an important topic. As a general practitioner (23 years service) and a primary care sports physician (17 years in a local sports injury clinic), the main difference between my two practices is the seven minute consultation in general practice and the 20 minute consultation at the sports clinic, with time for even longer consultations at the latter if required.

I do not believe that the NHS will ever be able to supply a comprehensive sport, exercise, and medicine service. My hope is that the recent fuss over viagra, xenical, relenza, and expensive high-tech procedures will lead to a realisation that a centrally funded, free at contact, tax based NHS is no longer a viable possibility. A very basic core service free at the point of use and funded by taxes and an insurance based or private service for other non-life-threatening conditions may emerge. Sport and exercise medicine may then find a place in the latter, hopefully. If the government is serious about elite sport, then it must find a means of funding the care of elite athletes via a different route. The time is right for a widespread debate on these matters, and I hope that the Journal will lead the way.

A B WALKER

Glasgow 